\title{
Development and Characterization of Hygroscopicity-Controlled Sustain Release Formulation of Divalproex Sodium
}

\author{
(D) Saurav ADHIKARI, (D) Uttam BUDHATHOKI*, (D) Panna THAPA \\ Kathmandu University, Drug Delivery Research Lab, Department of Pharmacy, Dhulikhel, Nepal
}

\begin{abstract}
Objectives: Divalproex sodium (DS), being a hygroscopic drug, requires low humidity during product manufacturing. This study aims to develop a hygroscopicity controlled sustained release formulation of DS that can be manufactured in relatively high humid conditions in facilities lacking dehumidifiers.

Materials and Methods: This study focuses on the role of polyethylene glycol (PEG-8000) and hydroxypropyl methylcellulose (HPMC K100M) as polymers of choice to control hygroscopicity and retard release of DS using solid dispersion technique. In this study, homogeneous solid dispersions containing various ratios of PEG-8000, HPMC K100M, and DS were obtained via melt granulation technique. Fifteen different solid dispersions were prepared based on Box-Behnken experimental design created in MiniTab software. The obtained solid dispersions were separately broken down into granules and their hygroscopic properties were determined via moisture uptake studies. Granular solid dispersions were then compressed into tablets and their sustained release dissolution profiles were studied as per the United States Pharmacopoeia (USP) monograph of DS extendedrelease tablets. Dissolution profiles of all fifteen formulations were then analyzed in Box-Behnken experimental design under MiniTab software to determine an optimized formulation having low hygroscopic properties as well as required multipoint drug release as per USP monograph. The final optimized formulation was prepared and subjected to moisture uptake study to determine its hygroscopicity, dissolution study to determine drug release kinetics and fourier transform infrared (FTIR) and differential scanning calorimetry (DSC) analysis to determine molecular interactions between drug and polymers.

Result: Optimized final formulation yielded granular solid dispersion with $28 \%$ less hygroscopicity compared to DS and tablets with an excellent release profile in accordance with USP monograph. FTIR and DSC analysis did not show any significant interaction between DS and components of the solid dispersion.
\end{abstract}

Conclusion: Optimized formulation from this study can be used to manufacture divalproex extended-release tablets inside facilities lacking dehumidifiers.

Key words: Divalproex sodium, solid dispersion, melt granulation, sustain release

\section{INTRODUCTION}

Oral drug delivery is the most preferred and convenient route of administration as the oral route provides maximum active surface area among all drug delivery systems for the administration of various drugs. Usually, conventional dosage forms produce wide fluctuations in the drug concentration in the bloodstream and tissues, causing undesirable toxicity and poor efficiency. These factors and others such as repetitive dosing and unpredictable absorption, lead to the concept of oral sustained release drug delivery systems.' Matrix-based system is a type of sustain release systems, where drug is dissolved or dispersed in a support resistant to disintegration. Drug is released from this support through erosion or diffusion. However, the release behavior is usually non-linear with a continuously diminishing release rate due to diffusion resistance or a decrease in effective surface area. ${ }^{2}$ 
Conventionally, solid dispersion has been defined as "the dispersion of one or more active ingredients in an inert carrier matrix in solid-state prepared by melting (fusion), solvent or melting-solvent method". ${ }^{3}$ Solid dispersion has been used in various applications to enhance the in vitro release of a drug compared to the conventional dosage form or to prepare water-insoluble drug polymer matrix to yield a modified release dosage form of a drug. ${ }^{4}$ It has also been widely used as a technique to mask taste of bitter drugs for application into rapidly disintegrating tablets. ${ }^{5}$ Although not widely adopted, another use of this technique is to modify the physical properties of a drug substance, such as conversion of hygroscopic/deliquescent drug into non-hygroscopic product in the form of solid dispersion. ${ }^{6}$

Response surface methodology (RSM) is a systematic way of establishing a relationship between any process input variable (independent variable) and it is response variable (dependent variable) to optimize the process. ${ }^{7}$ The independent/input variables are changed in a predefined and controlled manner while the response variables are observed as the output of the process. A relationship between the input and output variables is then established using mathematical models and regression techniques. Once a relationship is established, it can then be used to develop, improve or optimize the product or process. With the help of RSM, a process or product can be optimized using least number of experiments without affecting the accuracy of results. Unfortunately, qualitative variables cannot be optimized.

During an RSM study, the input variables are predefined based on various design of experiment (DoE) such as PlackettBurman design, Taguchi design, Full-Factorial design, Central composite design (CCD), Box-Behnken design, etc. Of these, Taguchi and Plackett-Burman designs are frequently used for screening studies, while Box-Behnken, Central composite, and factorial designs are frequently used for optimization studies. ${ }^{8}$

Divalproex sodium (DS), the model drug for this study, has been prescribed in various ailments such as seizures, bipolar disorder, and migraine headaches. ${ }^{9}$ Conventional dosage forms of divalproex need to be administered two to thrice per day to achieve desired pharmaceutical response..$^{10}$ When administered as extended release dosage form, $8-20 \%$ increase in dose is necessary to produce similar bioavailability as conventional dosage form. ${ }^{9}$ Despite this limitation, extended release dosage form is preferred owing to its decrease frequency of administration leading to better patient compliance and fewer side effects. Divalproex is available under the brand name, Depakote $^{\circledR}$, as delayed-release $(125,250$, and $500 \mathrm{mg})$ and extended-release tablets (250 and $500 \mathrm{mg}$ ). ${ }^{11}$

Sodium valproate and valproic acid, components of DS, are extremely stable under thermal stress conditions. ${ }^{12}$ Sodium valproate remains stable even after exposure to $110^{\circ} \mathrm{C}$ for 10 days and valproic acid does not show any sign of degradation after exposure to heat, light, and strong aqueous alkali or acid. ${ }^{12}$ Reddy et al. ${ }^{13}$ conducted force degradation studies in DS during which DS was subjected to an elevated temperature of $85^{\circ} \mathrm{C}$ for $120 \mathrm{~h}$. After the completion of the thermal stress period, the sample retained $100 \%$ chromatographic purity and did not contain any traces of degradation product.

DS is a hygroscopic powder, which makes it a challenging drug to develop into dosage forms under humid conditions. ${ }^{14}$ This study aims to ameliorate this problem by transforming DS into hygroscopicity controlled solid dispersion and use it to develop and optimized hygroscopicity controlled sustained release formulation of DS using Box-Behnken design.

\section{MATERIALS AND METHODS}

\section{Materials}

DS United States Pharmacopoeia (USP) was purchased from ROAQ Chemicals Pvt. Ltd. (India). Polyethylene glycol (PEG8000) was purchased from LAR-CHEM Industries (India). Hydroxypropyl methylcellulose (HPMC) K100M and lactose monohydrate were purchased from The Dow Chemical Company (USA) and Modern Dairy (China), respectively. Colloidal silicone dioxide (aerosil) was bought from Evonic Industries (Germany).

\section{Preliminary study}

Before performing RSM study, a preliminary study was conducted to produce solid dispersion with various ratios of PEG-8000, HPMC K100M and DS using the melt granulation technique. During this study, it was observed that PEG8000 melted at around $60^{\circ} \mathrm{C}$ and DS melted around $100^{\circ} \mathrm{C}$. To determine its thermal stability DS, it was heated up to $110^{\circ} \mathrm{C}$ for $30 \mathrm{~min}$ and allowed to cool down. Assay of the thermally stressed DS was conducted using liquid chromatography method mentioned in the USP monograph of DS. The results revealed an assay of $99.579 \%$ and it is chromatogram (Figure 1) did not show any secondary peak due to degradation product. The absence of secondary peak concurred with the findings of Chang ${ }^{12}$ and Reddy et al. ${ }^{13}$, suggesting the excellent thermal stability of DS. HPMC K100M did not melt, when it was heated individually, but was readily soluble, when added to the molten mixture of PEG-8000 and DS. When only two components PEG-

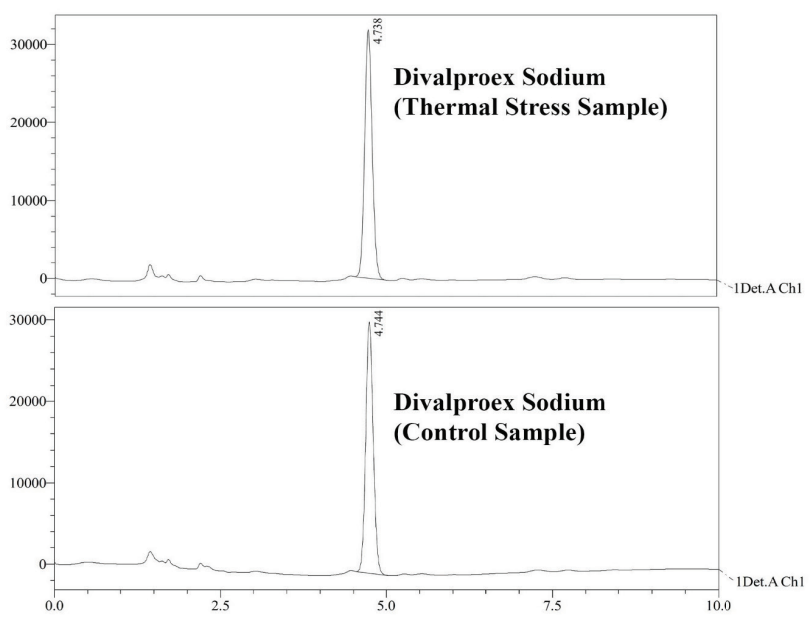

Figure 1. Chromatogram of DS thermal stress sample vs. control sample DS: Divalproex sodium 
8000 and DS were used to produce solid dispersion, it produced a homogeneous mixture at $100^{\circ} \mathrm{C}$, but phase separation was observed upon cooling, signifying very little molecular interaction between the two. When all three ingredients PEG8000, HPMC K100M, and DS were melted together, it produced a monophasic homogeneous mixture that did not show any sign of phase separation upon slow and fast cooling (shock cooling). Solid dispersions obtained after cooling were then broken down into granules. Hygroscopic properties of the obtained granular solid dispersion were determined using moisture uptake studies. Extragranullar HPMC K100M was added to the granular solid dispersion and compressed into tablets. Rate of drug release from the obtained tablets was then determined as per the USP monograph of DS extended-release tablets.

Based on the results obtained from moisture uptake and dissolution studies, upper and lower control limits of independent variables were set for the RSM.

\section{Design of experiment}

Three factors two level $\left(3^{2}\right)$ CCD was used for the optimization of formulation. For this purpose, Minitab 17 software was used.
Fifteen different formulations were obtained from the design (Table 1). Each formulation represented an experiment within the Box-Behnken design space. To avoid any potential bias, all experiments were conducted in randomized order (R1 to R15).

Since each formulation obtained from DoE contained a unique amount of PEG-8000, intragranular HPMC K100M and extragranular HPMC K100M, lactose monohydrate was added as diluent in each formulation to produce tablets with uniform weight and thickness (Table 2). Colloidal silicone dioxide (aerosila0.975\%) was used as a lubricating agent in all formulations. The final weight and thickness of tablet were set to be $615 \mathrm{mg}$ and $6.78 \pm 0.2 \mathrm{~mm}$, respectively. Dispensing of DS was performed at $25^{\circ} \mathrm{C}$ and $40 \%$ relative humidity $(\mathrm{RH})$. All other steps in the manufacturing process were performed at $25 \pm 2^{\circ} \mathrm{C}$ and $50 \pm 5 \% \mathrm{RH}$. Statistical analysis was not used in this study.

\section{Preparation of solid dispersion}

For the preparation of solid dispersion by fusion technique, following components of each formulation were melted together in a series of steps to produce a single homogeneous phase.

Table 1. Factors and level considered for design of experiment

\begin{tabular}{llll}
\multirow{2}{*}{ Levels (mg/Tab) } & Factors & & \\
\cline { 2 - 4 } & PEG-8000 & Intragranular HPMC K100M & Extragranular HPMC K100M \\
\hline Lower (-1) & $42 \mathrm{mg}$ & $66 \mathrm{mg}$ & $117 \mathrm{mg}$ \\
\hline Middle (0) & $84 \mathrm{mg}$ & $83 \mathrm{mg}$ & $133 \mathrm{mg}$ \\
\hline High (+1) & $126 \mathrm{mg}$ & $100 \mathrm{mg}$ & $150 \mathrm{mg}$ \\
\hline
\end{tabular}

PEG: Polyethylene glycol, HPMC: Hydroxypropyl methylcellulose

Table 2. Formulation design space created by Box-Behnken experimental design in Minitab

Formulation design space created in Minitab

\begin{tabular}{|c|c|c|c|c|c|c|c|}
\hline Run & PEG & Intragranular HMPC & Extragranular HPMC & DS & Aerosil & Lactose & Final Wt. \\
\hline $\mathrm{R} 2$ & 126 & 100 & 133 & 250 & 6 & 0 & 615 \\
\hline R3 & 126 & 83 & 150 & 250 & 6 & 0 & 615 \\
\hline R4 & 42 & 83 & 150 & 250 & 6 & 84 & 615 \\
\hline R6 & 42 & 66 & 133 & 250 & 6 & 118 & 615 \\
\hline R7 & 126 & 83 & 117 & 250 & 6 & 33 & 615 \\
\hline R8 & 84 & 83 & 133 & 250 & 6 & 59 & 615 \\
\hline R9 & 42 & 100 & 133 & 250 & 6 & 84 & 615 \\
\hline $\mathrm{R} 13$ & 42 & 83 & 117 & 250 & 6 & 117 & 615 \\
\hline R14 & 84 & 100 & 117 & 250 & 6 & 58 & 615 \\
\hline $\mathrm{R} 15$ & 84 & 83 & 133 & 250 & 6 & 59 & 615 \\
\hline
\end{tabular}

All weights are expressed in milligram (mg). PEG: Polyethylene glycol, HPMC: Hydroxypropyl methylcellulose, DS: Divalporex sodium 
Step 1: In a small stainless steel vessel, PEG-8000 was added and the container was gradually heated until the PEG melted. When the PEG melted completely, DS was gradually added with continuous stirring.

Step 2: At around $97^{\circ} \mathrm{C}$ to $98^{\circ} \mathrm{C}$, DS completely dissolved in PEG giving a transparent hot solution. In this solution, intragranular HPMC K100M was then gradually added with continuous stirring to obtain a translucent hot homogeneous mixture.

Step 3: The hot homogeneous phase obtained during fusion was then poured in stainless steel trays and allowed to cool gradually at room temperature $\left(25^{\circ} \mathrm{C}\right)$. Upon cooling, the molten liquid mass solidified to give a single homogeneous block of solid dispersion.

\section{Preparation of granules}

Solid dispersions were separately broken down into granules with the help of Multi Mill fitted with a screen of $1 \mathrm{~mm}$ pore size. Any residual material remaining in the Multi Mill was passed through a granulator fitted with a screen of $1 \mathrm{~mm}$ pore size to obtain free flowing granular solid dispersion. A small quantity of the obtained granular solid dispersion was subjected to moisture uptake studies and the remaining quantity was then mixed with appropriate amounts of extragranular HPMC K100M, lactose monohydrate, and aerosil as per experimental design (Table 2). A precompression study of granules was conducted in granules (Table 3 ).

\section{Moisture uptake studies}

Moisture sorption of compounds can be determined by exposing weighed amounts of compound in dishes placed in sealed desiccators containing saturated salt solutions. Saturated solutions of salts that give defined $\mathrm{RH}$ (as a function of temperature) have long been in use. ${ }^{15}$

A thin layer $(\approx 1.5 \mathrm{~g})$ of DS and granular solid dispersion were spread in separate glass beakers of capacity $25 \mathrm{~mL}$. The beakers were then placed in a desiccator containing a saturated salt solution that generates desired $\mathrm{RH}$. The desiccator was then stored in a constant temperature chamber $\left(30^{\circ} \mathrm{C}\right)$. At pre-determined time intervals, each sample was removed and covered with aluminum foil to prevent moisture exchange with the environment during weighing process. After being weighing, the dishes were immediately placed back into the desiccator. The net weight gain of each sample after each time interval was calculated and plotted in a graph.

Moisture sorption studies were conducted at $\mathrm{RH} 52 \%$ and $\mathrm{RH}$ $75 \%$ using saturated salt solutions of magnesium nitrate and sodium chloride, respectively.

\section{Compression into extended-release tablets}

The granules for each of the fifteen formulations were lubricated in a double cone blender before being compressed into $7 \mathrm{~mm}$ long oval tablets of weight $615 \mathrm{mg}$ and thickness $6.78 \pm 0.2 \mathrm{~mm}$.

\section{RESULTS}

Evaluation of formulations within the design space

Moisture uptake studies

After exposure of $24 \mathrm{~h}$ at $\mathrm{RH} 75 \%$, granular solid dispersion from all fifteen formulations absorbed a greater amount of moisture compared to DS (Figure 2). It has been reported that

Table 3. Precompression study of granules

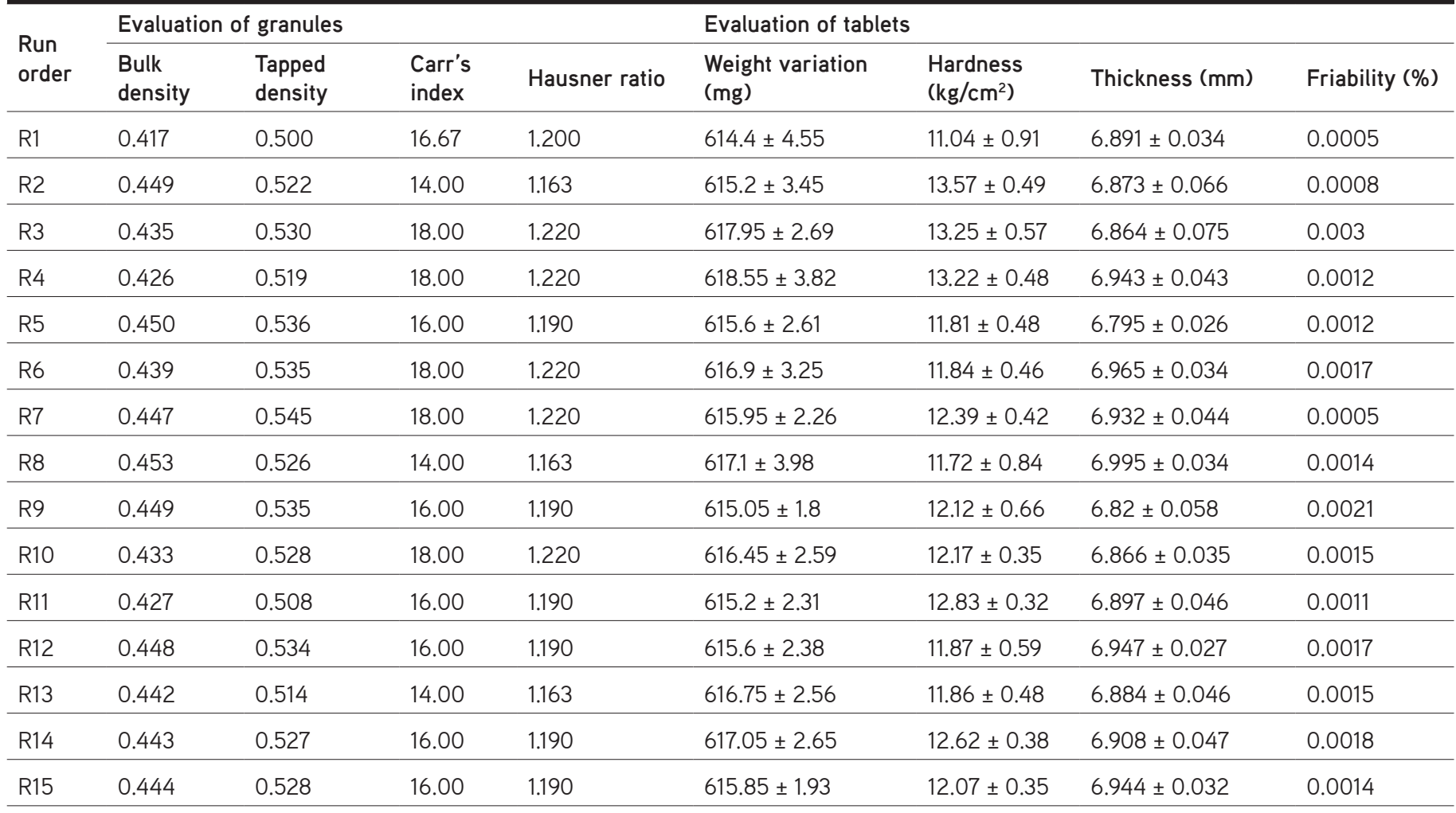


HPMC starts swelling at RH greater than $65 \%$. $^{16}$ This might be the reason for increased moisture sorption by solid dispersion at $\mathrm{RH} 75 \%$ (Figure 2).

A moisture sorption study at $\mathrm{RH} 52 \%$ was continued for $48 \mathrm{~h}$. At the end of $48 \mathrm{~h}$ all fifteen formulations absorbed less moisture compared to DS (Figure 3).

\section{Evaluation of granules and tablets}

Granules from all fifteen formulations were evaluated to determine their bulk density, tapped density, Carr's index, and Hausner's ratio. Tablets were evaluated for their weight

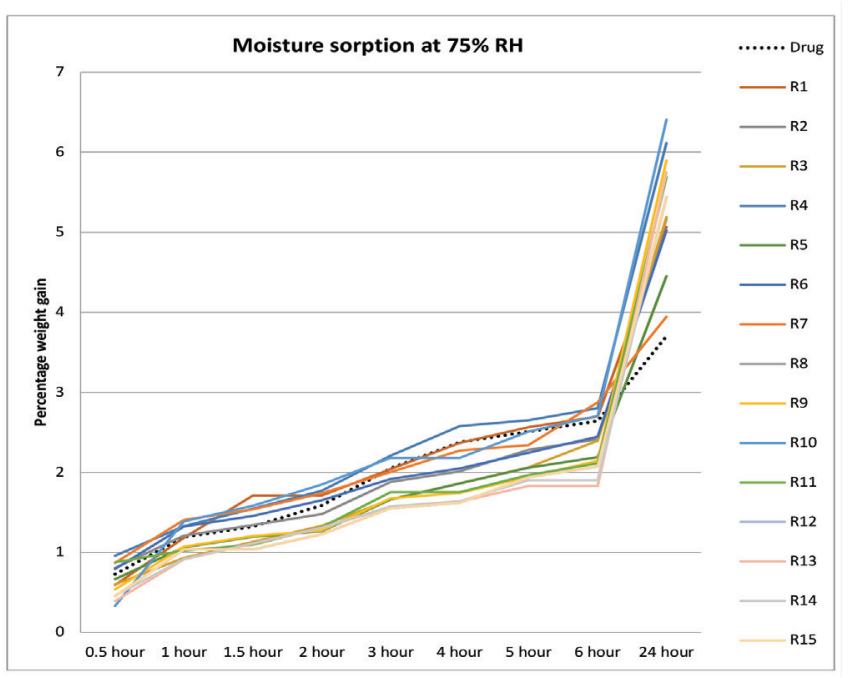

Figure 2. Moisture sorption by various formulations at $75 \% \mathrm{RH}$ $\mathrm{RH}$ : Relative humidity variation, hardness thickness, friability, dissolution, and assay. Dissolution (dissolution test-2) and assay were performed using respective HPLC methods mentioned under USP monograph of divalproex ER tablets in USP $40 .^{17}$

\section{Final optimized formulation}

After the completion of all fifteen experiments within the design space, data obtained from dissolution studies (Table 4 and Figure 4) and moisture sorption studies (Figure 3) were recorded in the Box-Behnken design previously created in MINITAB 17 and analyzed to obtain optimized dissolution parameters (Table 5).

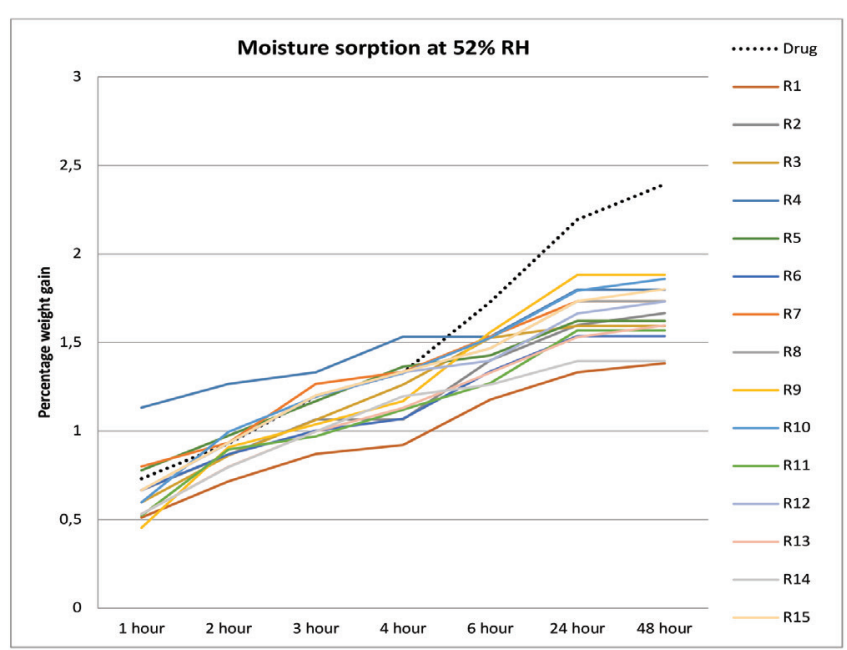

Figure 3. Moisture sorption by various formulations at $52 \% \mathrm{RH}$ $\mathrm{RH}$ : Relative humidity

Table 4. Dissolution profile and assay of compressed tablets

\begin{tabular}{|c|c|c|c|c|c|}
\hline \multirow{2}{*}{ Run order } & \multicolumn{4}{|c|}{ Dissolution profile (\% release) } & \multirow{2}{*}{ Assay (\% } \\
\hline & $3^{\text {rd }}$ hour & $9^{\text {th }}$ hour & $12^{\text {th }}$ hour & $21^{\text {st }}$ hour & \\
\hline $\mathrm{R} 1$ & $29.69 \pm 0.25$ & $68.65 \pm 1.88$ & $79.99 \pm 4.29$ & $99.18 \pm 4.42$ & 99.76 \\
\hline $\mathrm{R} 2$ & $29.41 \pm 1.09$ & $76.04 \pm 2.69$ & $83.95 \pm 2.18$ & $101.58 \pm 1.97$ & 100.59 \\
\hline R3 & $20.79 \pm 1.84$ & $70.12 \pm 2.86$ & $81.8 \pm 4.94$ & $92.65 \pm 1.21$ & 99.57 \\
\hline R4 & $21.61 \pm 1.04$ & $69.03 \pm 2.42$ & $77.97 \pm 2.96$ & $92.59 \pm 1.43$ & 99.35 \\
\hline R5 & $28.08 \pm 1.31$ & $67.38 \pm 3.56$ & $76.17 \pm 3.39$ & $96.37 \pm 0.38$ & 98.93 \\
\hline R6 & $28.22 \pm 1.25$ & $71.54 \pm 1.77$ & $84.8 \pm 2.05$ & $95.43 \pm 4.24$ & 99.41 \\
\hline $\mathrm{R} 7$ & $31.7 \pm 4.43$ & $77.28 \pm 2.36$ & $86.3 \pm 0.61$ & $99.15 \pm 2.16$ & 100.83 \\
\hline R8 & $29.14 \pm 1.27$ & $72.33 \pm 0.49$ & $83.14 \pm 1.8$ & $99.28 \pm 0.85$ & 99.67 \\
\hline R9 & $27.19 \pm 1.48$ & $68.32 \pm 3.76$ & $80.69 \pm 2.89$ & $104.11 \pm 2.11$ & 100.46 \\
\hline $\mathrm{R} 10$ & $33.94 \pm 1.33$ & $78.37 \pm 2.31$ & $93.74 \pm 4.6$ & $107.12 \pm 3.13$ & 100.59 \\
\hline R11 & $26.61 \pm 1.44$ & $71.68 \pm 2.65$ & $87.04 \pm 2.19$ & $103.13 \pm 2.19$ & 99.85 \\
\hline $\mathrm{R} 12$ & $29.3 \pm 2.09$ & $72.01 \pm 1.03$ & $82.55 \pm 1.84$ & $99.57 \pm 2.48$ & 99.53 \\
\hline $\mathrm{R} 13$ & $28.24 \pm 0.68$ & $72.43 \pm 1.25$ & $83.42 \pm 0.8$ & $105 \pm 2.1$ & 101.26 \\
\hline $\mathrm{R} 14$ & $25.72 \pm 1.21$ & $70.63 \pm 1.77$ & $82.62 \pm 1.65$ & $98.09 \pm 2.63$ & 100.79 \\
\hline $\mathrm{R} 15$ & $29.16 \pm 2.29$ & $72.27 \pm 0.59$ & $83.32 \pm 2.11$ & $99.64 \pm 2.39$ & 100.38 \\
\hline
\end{tabular}


Optimized formulation (Tables 6, 7 and Figure 5) obtained from Minitab was manufactured using same process as previous formulations. Moisture sorption of the optimized formulation at $52 \% \mathrm{RH}$ is shown in Figure 6. The dissolution profile of the optimized formulation was found within the limit of USP (Figure 7).

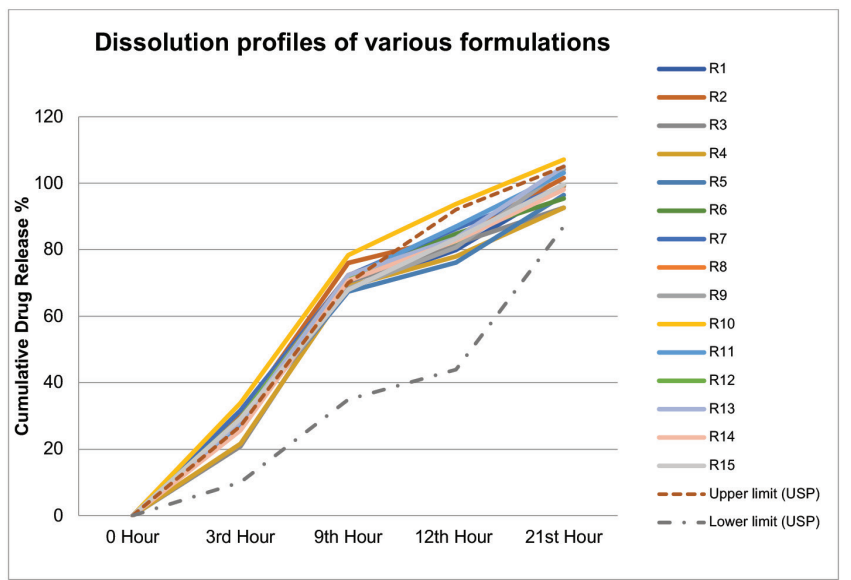

Figure 4. Dissolution profile of tablets before optimization

Table 5. Target dissolution parameters set in Minitab for optimized formulation

\begin{tabular}{ll}
$3^{\text {rd }}$ hour & $24 \%$ release \\
\hline $9^{\text {th }}$ hour & $65 \%$ release \\
\hline $12^{\text {th }}$ hour & $78 \%$ release \\
\hline $21^{\text {st }}$ hour & $95 \%$ release \\
\hline
\end{tabular}

\section{Drug release kinetics}

The rate of drug release from the final optimized formulation was fitted into various models of drug release kinetics (Table 8).

\section{Infrared absorption spectroscopy}

Infrared absorption spectroscopy was performed on API and the developed solid dispersion (Figure 8 and Table 9).

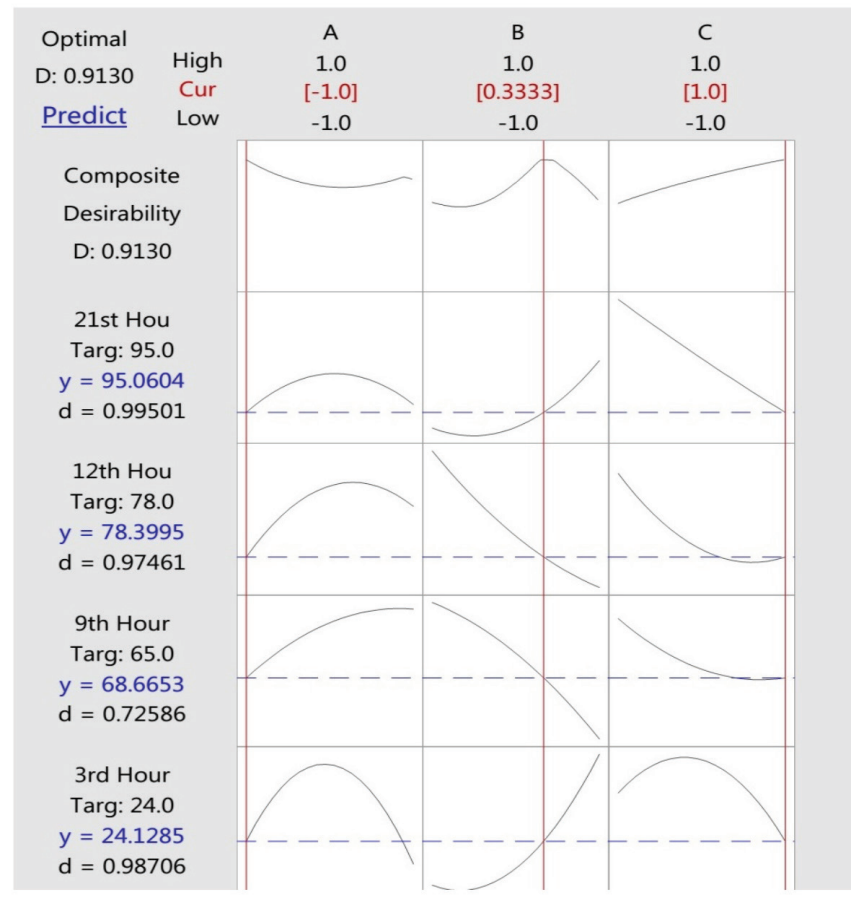

Figure 5. Optimization plot obtained in Minitab

Table 6. Composition given by Minitab for optimized formulation

\begin{tabular}{llll} 
& PEG (A) & Intragranular HPMC (B) & Extragranular HPMC (C) \\
\hline Levels in Box-Behnken design & -1 & 0.33 & +1 \\
\hline Actual value & $42 \mathrm{mg}$ & $88.66 \mathrm{mg}$ & $150 \mathrm{mg}$ \\
\hline
\end{tabular}

PEG: Polyethylene glycol, HPMC: Hydroxypropyl methylcellulose

\section{Table 7. Optimized formulation obtained from Minitab}

\begin{tabular}{lll} 
S. no & Raw material & Quantity $(\mathrm{mg})$ \\
\hline 1 & Divalporex sodium & 250 \\
\hline 2 & PEG-800 & 42 \\
\hline 3 & HPMC K100M intragranular & 88.66 \\
\hline 4 & HPMC K100M extragranular & 150 \\
\hline 5 & Aerosil & 6 \\
\hline 6 & Lactose monohydrate & 78.34 \\
\hline & Total & 615 \\
\hline
\end{tabular}

PEG: Polyethylene glycol, HPMC: Hydroxypropyl methylcellulose 


\section{Differential scanning calorimetry (DSC)}

DSC analysis was performed on the final optimized solid dispersion and its individual components (Figure 9).

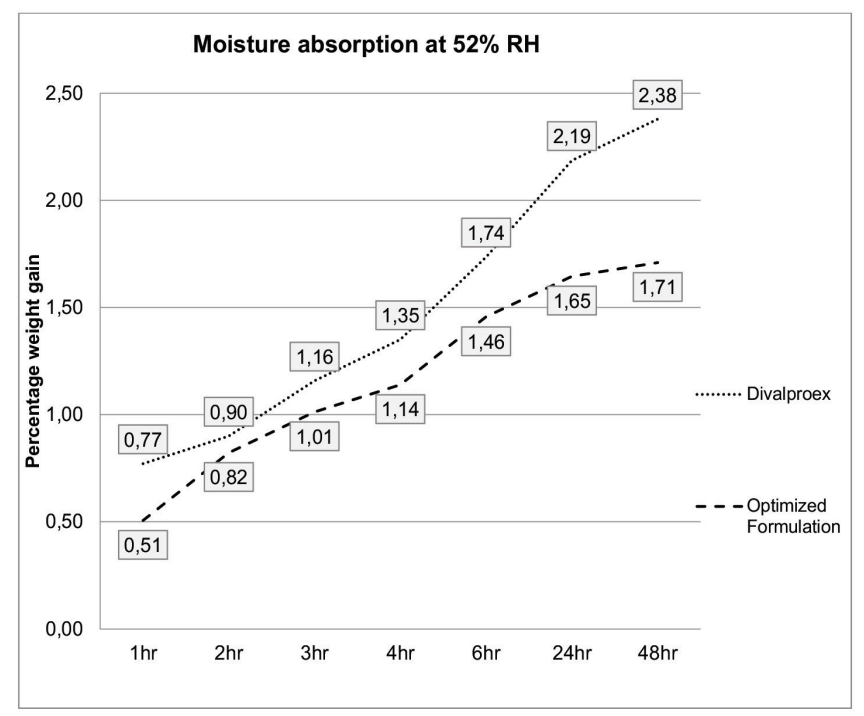

Figure 6. Moisture sorption of optimized formulation at $52 \% \mathrm{RH}$

\section{DISCUSSION}

The final optimized formulation when subjected to moisture sorption studies at $52 \% \mathrm{RH}$ produced granules with $1.71 \%$ weight gain at the end of $48 \mathrm{~h}$. During the same period, DS

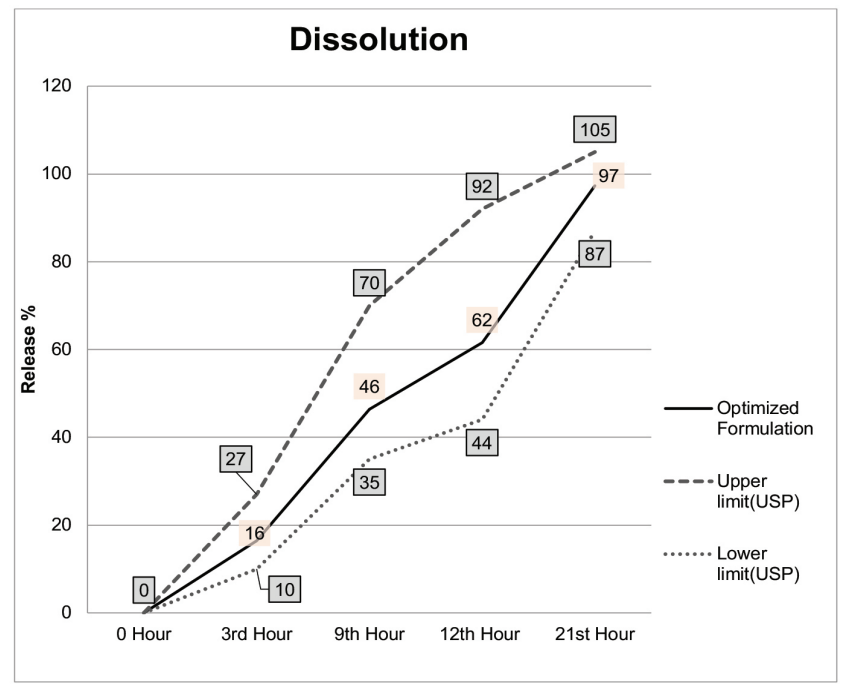

Figure 7. Dissolution profile of optimized formulation USP: United States Pharmacopoeia

Table 8. Drug release kinetics fitted to various models

\begin{tabular}{llll} 
S. no & Kinetics & Regression equation & $\mathbf{R}^{\mathbf{2}}$ \\
\hline 1 & Zero order & $\mathrm{y}=4.6439 x+2.5423$ & 0.995 \\
\hline 2 & First order & $\mathrm{y}=-0.0727 \mathrm{x}+2.1873$ & 0.876 \\
\hline 3 & Huguchi model & $\mathrm{y}=21.087 \mathrm{x}-9.5554$ & 0.938 \\
\hline 4 & Korsmeyer-Peppas & $\mathrm{K}=5.689, \mathrm{n}=0.9573$ & 0.9999 \\
\hline 5 & Hixson-Crowell & $\mathrm{y}=-0.1526 \mathrm{x}+4.8832$ & 0.952 \\
\hline
\end{tabular}

Table 9. Intrepretation of IR spectrum of DS and its solid dispersion

\begin{tabular}{|c|c|c|c|c|}
\hline \multirow{2}{*}{ S. no } & \multirow{2}{*}{ Wavenumber } & \multicolumn{2}{|c|}{ Percentage transmittance } & \multirow{2}{*}{ Remarks } \\
\hline & & Divalproex sodium & DS solid dispersion & \\
\hline 1 & $2957 \mathrm{~cm}^{-1}$ & $87.74 \%$ & $82.26 \%$ & Asymmetric $\mathrm{C}-\mathrm{H}$ stretch of $\mathrm{CH} 3 .^{18}$ \\
\hline 2 & $2933 \mathrm{~cm}^{-1}$ & $88.50 \%$ & $83.76 \%$ & Asymmetric $\mathrm{C}-\mathrm{H}$ stretch of $\mathrm{CH} 2 .{ }^{18}$ \\
\hline 3 & $2873 \mathrm{~cm}^{-1}$ & $91.15 \%$ & $86.29 \%$ & Symmetric $\mathrm{C}-\mathrm{H}$ stretch of $\mathrm{CH} 3 .^{18}$ \\
\hline 4 & $1689 \mathrm{~cm}^{-1}$ & $87.75 \%$ & $83.63 \%$ & $\mathrm{C}=\mathrm{O}$ stretch of valproic acid. ${ }^{19}$ \\
\hline 5 & $1555 \mathrm{~cm}^{-1}$ & $84.09 \%$ & $79.64 \%$ & $\mathrm{C}=\mathrm{O}$ stretch of valproate ion. ${ }^{19}$ \\
\hline 6 & $1465 \mathrm{~cm}^{-1}$ & $88.73 \%$ & $84.59 \%$ & $\mathrm{C}-\mathrm{H}$ bend/scissoring in $\mathrm{CH} 2 .^{18}$ \\
\hline 7 & $1379 \mathrm{~cm}^{-1}$ & $84.39 \%$ & $79.99 \%$ & $\mathrm{C}-\mathrm{H}$ rocking in $-\mathrm{CH} 3 .{ }^{21}$ \\
\hline 8 & $1256 \mathrm{~cm}^{-1}$ & $82.28 \%$ & $77.38 \%$ & \multirow{2}{*}{-} \\
\hline 9 & $1217 \mathrm{~cm}^{-1}$ & $81.69 \%$ & $77.07 \%$ & \\
\hline 10 & $1107 \mathrm{~cm}^{-1}$ & $85.60 \%$ & $73.37 \%$ & $\begin{array}{l}\mathrm{C}-\mathrm{O} \text { stretching vibrations in } \mathrm{C}-\mathrm{O}-\mathrm{C} \text { bond of } \\
\mathrm{PEG}{ }^{20}\end{array}$ \\
\hline
\end{tabular}

IR: Infrared spectroscopy, DS: Divalporex sodium, PEG: Polyethylene glycol 
gained $2.38 \%$. Hence, the solid dispersion was $28.15 \%$ less hygroscopic compared to DS. At the end of $48 \mathrm{~h}$ solid dispersion remained free flowing granules, whereas DS had clumped together into a single mass.

Drug release kinetics from the optimized tablet formulation most closely resembles Korsmeyer-Peppas model of drug release with a correlation coefficient $r^{2}=0.999$. The values of $K$ and $n$ in the Korsmeyer-Peppas equation were found to be 5.689 and 0.9573 , respectively. Since the value of $n$ is close to 1 , we can conclude that the drug release approaches zero order kinetics, which is also evident from the correlation coefficient $r^{2}=0.995$ for zero order approximations (Table 8). In a similar study, Monajjemzadeh et al..$^{14}$ produced sustained release formulation of DS via a direct compression method using HPMC K100M as rate controlling polymer, where they also found zero order drug release $\left(r^{2}=0.995\right)$. This implies that release kinetics in

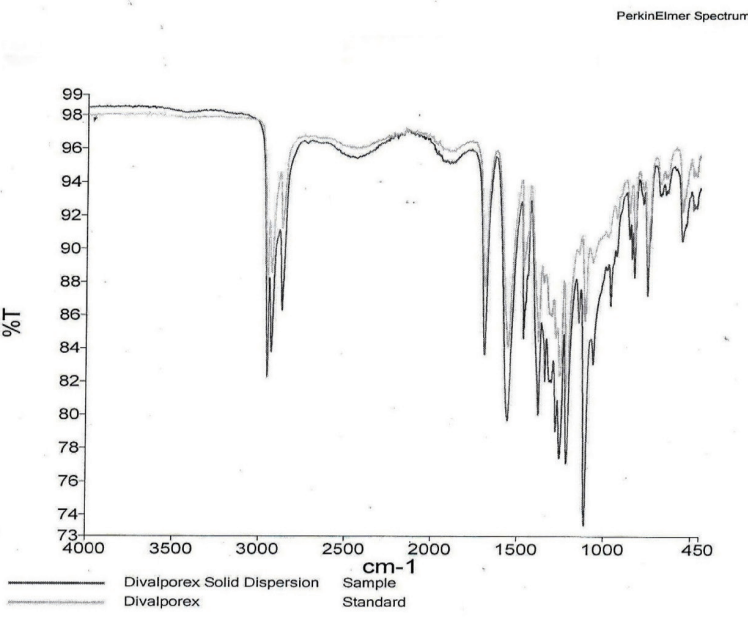

Figure 8. Comparison of IR spectra of DS and DS solid dispersion DS: Divalproex sodium, IR: Infrared spectroscopy

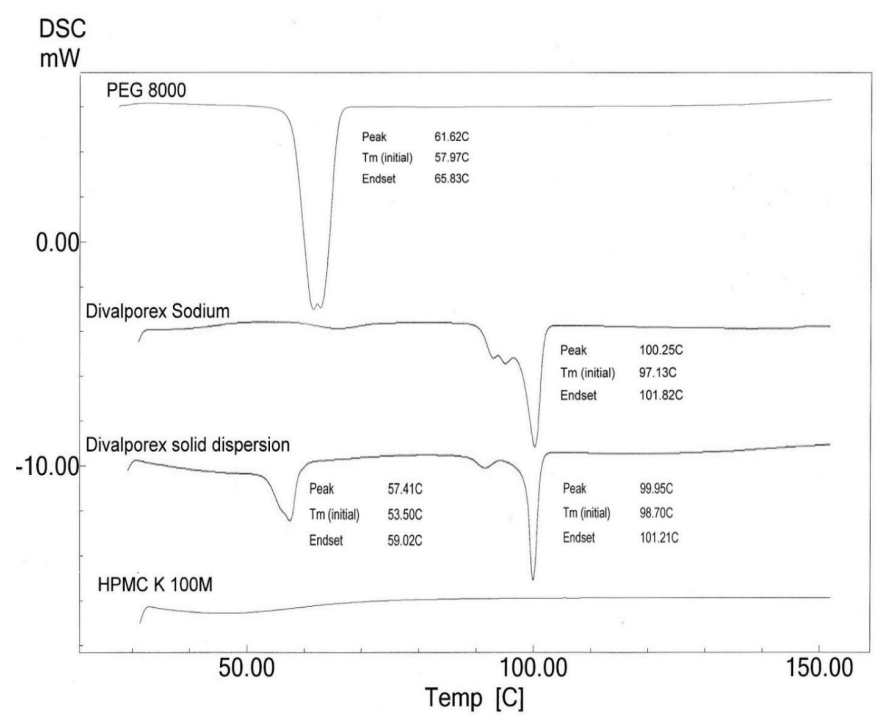

Figure 9. Melting endotherm of DS solid dispersion and its components DS: Divalporex sodium, DSC: Differential scanning calorimetry both cases were predominantly governed by high solubility and diffusivity of DS, and not by the technology (direct compression vs. solid dispersion) used to manufacture the tablets.

A study on IR spectrum of DS has shown that absorbance at $2957 \mathrm{~cm}^{-1}$ is due to asymmetric $\mathrm{C}-\mathrm{H}$ stretch of $\mathrm{CH}_{3}{ }^{18}$ Another study on IR spectrum of DS has shown that absorbance at 1555 $\mathrm{cm}^{-1}$ and $1689 \mathrm{~cm}^{-1}$ is associated with carbonyl bonds of sodium valproate and valproic acid, respectively. ${ }^{19}$ Any significant interaction between carbonyl groups of divalproex and other components of solid dispersion would mean shift of these frequencies in IR spectrum of DS solid dispersion. This shift is absent and absorption at $1555 \mathrm{~cm}^{-1}$ and $1689 \mathrm{~cm}^{-1}$ is seen in the IR spectra of DS solid dispersion as well. This implies absence of carbonyl type interaction between DS and other polymers in solid dispersion.

The sharp peak around $99^{\circ} \mathrm{C}$ in the endotherm of DS represents evaporation of valproic acid. ${ }^{19}$ DS and DS solid dispersion both produced identical endothermic peaks at $100.25^{\circ} \mathrm{C}$ and $99.95^{\circ} \mathrm{C}$, respectively. Such close values of $T_{m}$ imply absence of any molecular forces/interaction between valproic acid and components of the solid dispersion that could have significantly altered the endothermic peak shape or $T_{m}$ in the endotherm of the DS solid dispersion. This supports the findings from the IR spectrum analysis, which also suggests absence of molecular interaction.

There is a significant difference in IR transmittance at $1107 \mathrm{~cm}^{-1}$ between DS (85.60\%) and DS solid dispersion (73.37\%), 12.23\% greater absorption by solid dispersion at $1107 \mathrm{~cm}^{-1}$. Dinç and Guner $^{20}$ have reported that absorbance band of PEG at 1107 $\mathrm{cm}^{-1}$ is associated with $\mathrm{C}-\mathrm{O}$ stretch when the $\mathrm{C}-\mathrm{O}$ bond of PEG is involved in intermolecular hydrogen bonding, suggesting that the $\mathrm{C}-\mathrm{O}$ bond of PEG in DS solid dispersion is involved in hydrogen bonding possibly with water molecules, resulting in greater absorbance by solid dispersion. This interpretation is also supported by the fact that $\mathrm{T}_{\mathrm{m}}$ value in melting endotherm of pure PEG-8000 $\left(61.62^{\circ} \mathrm{C}\right)$ has decreased to $57.41^{\circ} \mathrm{C}$ in endotherm of solid dispersion. Majumdar et al. ${ }^{21}$ have observed a similar decrease in $T_{m}$ value in melting endotherm of PEG due to interactions between water molecule and PEG molecule. This also suggests the presence of interactions between water and PEG molecules in the DS solid dispersion.

\section{Study limitations}

X-ray diffraction study could not be performed. This could have enabled a further understanding of molecular interactions and the degree of crystallinity within solid dispersion.

\section{CONCLUSION}

DS is present in solid dispersion without any significant molecular interaction between divalproex and polymers of solid dispersion. Moisture present in DS solid dispersion is associated with PEG molecule as evident from shift in $T_{m}$ of PEG and sharp increase in absorbance by solid dispersion at $1107 \mathrm{~cm}^{-1}$. Since the interaction is absent, the decrease in hygroscopicity of DS solid dispersion compared to DS may be because of PEG/HPMC acting as a barrier between the drug 
and moisture. The optimized formulation from this study can be used to manufacture divalproex extended-release tablets inside facilities lacking humidity controlling systems such as dehumidifiers.

\section{Ethics}

Ethics Committee Approval: Not required.

Informed Consent: Not required.

Peer-review: Externally peer-reviewed.

\section{Authorship Contributions}

Concept: S.A., U.B., P.T., Design: U.B., P.T., Data Collection or Processing: S.A., Analysis, or Interpretation: S.A., U.B., P.T., Literature Search: S.A., U.B., P.T., Writing: S.A., U.B., P.T.

Conflict of Interest: No conflict of interest was declared by the authors.

Financial Disclosure: Part of academic dissertation, thus funded by Department of Pharmacy, Kathmandu University.

\section{REFERENCES}

1. Ratnaparkni MP, Gupta Jyoti P. Sustained release oral drug delivery system - an overview. Int J Pharma Res Rev. 2013;2:11-21.

2. Khan GM. Controlled release oral dosage forms: some recent advances in matrix type drug delivery systems. J Med Sci Res. 2001;1:350-354.

3. Chiou WL, Riegelman S. Pharmaceutical applications of solid dispersion systems. J Pharm Sci. 1971;60:1281-1302.

4. Craig $D Q$. The mechanisms of drug release from solid dispersions in water-soluble polymers. Int J Pharm. 2002;231:131-144.

5. Becker K, Salar-Behzadi S, Zimmer A. Solvent-free melting techniques for the preparation of lipid-based solid oral formulations. Pharm Res. 2015;32:1519-1545.

6. Trivedi JS, Gokhale RD. Solid dispersions comprising a hygroscopic and/ or deliquescent drug. 2005; (US 2005/0013856 A1).

7. Fukuda IM, Pinto CFF, dos Santos Moreira C, Saviano AM, Lourenço FR. Design of experiments (DoE) applied to pharmaceutical and analytical quality by design (QbD). Brazilian J Pharm Sci. 2018;54.

8. Bhoop BS, Raza K, Beg S. Developing “optimized" drug products employing “designed" experiments. Chem Ind Dig. 2013;23:70-76.
9. Dutta S, Reed RC. Divalproex to divalproex extended release conversion. Clin Drug Investig. 2004;24:495-508.

10. Phaechamud T, Mueannoom W, Tuntarawongsa S, Chitrattha S. Preparation of coated valproic acid and sodium valproate sustainedrelease matrix tablets. Indian J Pharm Sci. 2010;72:173-183.

11. Dutta S, Zhang Y, Selness DS, Lee LL, Williams LA, Sommerville KW. Comparison of the bioavailability of unequal doses of divalproex sodium extended-release formulation relative to the delayed-release formulation in healthy volunteers. Epilepsy Res. 2002;49:1-10.

12. Chang ZL. Sodium valproate and valproic acid. Anal Profiles Drug Subst Excipients. 1979;8:529-556.

13. Reddy SR, Reddy KH, Reddy PM, Reddy GA, Kumar MN, Sharma HK. Reliable GC method for related substances in divalproex sodium drug. J Chromatogr Sci. 2017;55:891-898.

14. Monajjemzadeh F, Hamishehkar H, Zakeri-Milani P, Farjami A, Valizadeh $H$. Design and optimization of sustained-release divalproex sodium tablets with response surface methodology. AAPS PharmSciTech. 2013;14:245-253.

15. Niazi S. Handbook of preformulation: chemical, biological, and botanical drugs. $1^{\text {st }}$ ed. Informa Healthcare; 2007:229-230.

16. Laksmana FL, Kok PJ, Frijlink HW, Vromans H, Van der Voort Maarschalk $K$. Using the internal stress concept to assess the importance of moisture sorption-induced swelling on the moisture transport through the glassy HPMC films. AAPS PharmSciTech. 2008;9:891-898.

17. Convention USP. U.S. Pharmacopeia National Formulary 2017: USP 40 NF 35. The United States Pharmacopeial Convention, 12601 Twinbrook Parkway, Rockville, MD 20852; 2017.

18. Coates J. Interpretation of infrared spectra, a practical approach. Encycl Anal Chem. Published online 2006.

19. Petrusevski G, Naumov P, Jovanovski G, Bogoeva-Gaceva G, Ng SW. Solid-state forms of sodium valproate, active component of the anticonvulsant drug epilim. ChemMedChem. 2008;3:1377-1386.

20. Dinç CÖ, Guner A. Solid-state characterization of poly(ethylene glycol) samples prepared by solvent cast technique. Bulg Chem Commun. 2017;49:15-20.

21. Majumdar R, Alexander KS, Riga AT. Physical characterization of polyethylene glycols by thermal analytical technique and the effect of humidity and molecular weight. Pharmazie. 2010;65:343-347. 